\title{
Food security under high bioenergy demand toward long-term climate goals
}

\author{
Tomoko Hasegawa ${ }^{1,2,3}$ (D) $\cdot$ Ronald D. Sands ${ }^{4} \cdot$ Thierry Brunelle $^{5} \cdot$ Yiyun Cui $^{6}$. \\ Stefan Frank ${ }^{3}$ - Shinichiro Fujimori ${ }^{2,3,7}$ - Alexander Popp ${ }^{8}$
}

Received: 12 April 2018 / Accepted: 17 August 2020/Published online: 26 August 2020

(C) The Author(s) 2020

\begin{abstract}
Bioenergy is expected to play an important role in the achievement of stringent climatechange mitigation targets requiring the application of negative emissions technology. Using a multi-model framework, we assess the effects of high bioenergy demand on global food production, food security, and competition for agricultural land. Various scenarios simulate global bioenergy demands of 100, 200, 300, and 400 exajoules (EJ) by 2100 , with and without a carbon price. Six global energy-economy-agriculture models contribute to this study, with different methodologies and technologies used for bioenergy supply and greenhouse-gas mitigation options for agriculture. We find that the large-scale use of bioenergy, if not implemented properly, would raise food prices and increase the number of people at risk of hunger in many areas of the world. For example, an increase in global bioenergy demand from 200 to 300 EJ causes a $-11 \%$ to $+40 \%$ change in food crop prices and decreases food consumption from -45 to $-2 \mathrm{kcal}^{\text {person }}{ }^{-1}$ day $^{-1}$, leading to an additional 0 to 25 million people at risk of hunger compared with the case of no bioenergy demand (90th percentile range across models). This risk does not rule out the intensive use of bioenergy but shows the importance of its careful implementation, potentially including regulations that protect cropland for food production or for the use of bioenergy feedstock on land that is not competitive with food production.
\end{abstract}

Keywords Bioenergy $\cdot$ Food security $\cdot$ Food availability $\cdot$ Model comparison $\cdot$ Integrated assessment model

This article is part of the Special Issue on "Assessing Large-scale Global Bioenergy Deployment for Managing Climate Change (EMF-33)" edited by Steven Rose, John Weyant, Nico Bauer, Shinichiro Fuminori, Petr Havlik, Alexander Popp, Detlef van Vuuren, and Marshall Wise.

Electronic supplementary material The online version of this article (https://doi.org/10.1007/s10584-02002838-8) contains supplementary material, which is available to authorized users.

Tomoko Hasegawa

thase@fc.ritsumei.ac.jp

Extended author information available on the last page of the article 


\section{Introduction}

Land-based mitigation options play an important role in the assessment of stringent climate mitigation policies (Popp et al. 2014b, 2017). Bioenergy should be in high demand because carbon is absorbed directly from the atmosphere (negative emission) when combined with carbon capture and storage. However, potential competition for land between food and bioenergy crop production is of concern. The large-scale use of bioenergy, to support stringent temperature ceilings of 2 or $1.5^{\circ} \mathrm{C}$ by the end of this century, would change land dynamics, put pressure on land resources (Popp et al. 2014b), compete with food production, and increase the risk of hunger in middle- and low-income regions (Frank et al. 2017; Hasegawa et al. 2015a, 2018). The use of bioenergy to replace fossil fuels is addressed in other studies (e.g., Hasegawa et al. 2018; Bauer et al. 2018) but not in the context of food security. This study provides an in-depth analysis of the relationship between bioenergy and use of land for meeting food demand.

Researchers have assessed the amounts of bioenergy and afforestation required under various climate policy scenarios and potential effects on food markets. For example, bioenergy amounts of 100-200 exajoules (EJ) in 2050 and 200-300 EJ in 2100 have been estimated for strong climate stabilization; these amounts correspond to approximately 200-500 and 2001500 Mha cropland for bioenergy in 2050 and 2100, respectively (approximately 10-30 and $10-100 \%$ of the current cropland area, respectively) (FAO 2016; Popp et al. 2017; Rose et al. 2014). In these studies, the amount of forested land is estimated to increase to 150 Mha by 2050 through afforestation and the avoidance of deforestation. A major portion of this land conversion happens on other natural land types, but the increases in forest and bio-crop land areas put pressure on land resources, leading to increases in crop yield and decreases in cropland and pasture areas. Popp et al. (2017) reported a $110 \%$ average food price increase from 2005 to 2100 due to competition for land between food and land-based mitigation options. In this prior analysis, the bioenergy demand differs among such models due to differences in mitigation options and best representations of climate-change mitigation strategies.

The impacts of climate mitigation on food security depend on the quantity and feedstock types of bioenergy applied to achieve emission reduction. Some studies have shown that largescale bioenergy implementation would be the most efficient mitigation option among technological possibilities to achieve stringent mitigation (e.g., Havlík et al. 2015, whereas other models have shown that large-scale bioenergy production can be a major contributor to food insecurity (e.g., Hasegawa et al. 2015a, 2018). The response to climate mitigation in each model depends on the set of mitigation options, their costs, the bioenergy feedstock, and the selection mechanism. Existing single-model studies have been conducted with distinct climatepolicy stringency and socioeconomic assumptions, rendering the derivation of robust conclusions across studies difficult. Thus, a multi-model inter-comparison that harmonizes bioenergy demand, carbon prices, and socioeconomic factors would enable direct comparison of model responses to a given bioenergy demand.

Lotze-Campen et al. (2014) performed a multi-model inter-comparison that assessed bioenergy effects on agricultural markets by harmonizing the biomass demand for energy use (100 EJ in 2050). The authors conclude that this level of biomass demand has negligible effects on the agricultural market compared with climate change impacts. However, more stringent climate mitigation in line with the Paris Agreement (UNFCCC 2015) requires two or three times as much bioenergy (200-300 EJ year ${ }^{-1}$ ) and would raise concerns about higher 
food prices and food insecurity. Although a high demand for bioenergy increases food security concerns, no study has involved the harmonization of bioenergy demand and carbon prices across models while directly addressing the effects of bioenergy demand on food security and the risk of hunger.

This study is the first multi-model comparison to directly address the relationship between large bioenergy demands and food security. The output from the model ensemble helps to identify areas of consensus and uncertainty that would not be found with any single model. Our study extends the existing literature in several ways. First, we use a set of scenarios with different levels of bioenergy demand, which allows us to examine the bioenergy effect on food security systematically. The demonstration of a relationship between bioenergy supply and food consumption will be useful for the estimation of additional agricultural productivity requirements. Second, we estimate the number of people at risk of hunger as an indicator that is relevant to sustainable development goal (SDG2), which is to end hunger and improve nutrition and agricultural practices. Whereas Hasegawa et al. (2018) analyzed the impacts of climate mitigation on the risk of hunger, this study focuses on the impact of a specific mitigation measure: bioenergy. Third, this study addresses multiple dimensions of food security by using several related indicators that provide a dynamic perspective on the concept.

\section{Methods}

Food security is a complex multi-dimensional issue involving food availability, access, utility, and stability (FAO 2016). To provide a dynamic perspective on this concept, we use as many indicators as possible, including the undernourished population; per-capita dietary energy consumption; food price; food self-sufficiency (production/consumption) ratio; cropland areas for food production, feed production, and pasture; and crop and livestock production and their regional allocations by country and region. Food production, agricultural land used for food production, and per-capita dietary energy consumption represent food availability; the food self-sufficiency ratio represents food stability; and the remaining indicators represent food access (FAO 2016). All of these indicators except the undernourished population are direct outputs of the models; the undernourished population is calculated as a post-process.

To project the undernourished population, we adopt the methodology of the United Nations Food and Agriculture Organization (FAO): a probability distribution framework documented in Cafiero (2014) and used by Fujimori et al. (2019) and Hasegawa et al. 2015a, b, 2018. The definition of undernourishment or hunger is a state of energy (calorie) deprivation lasting for more than 1 year; this concept does not include the short-lived effects of temporary crises or inadequate intake of other essential nutrients (FAO 2016). The undernourished population is a multiple of the prevalence of the undernourished ( $\mathrm{PoU}$ ) and the total population.

The PoU is calculated using the mean dietary energy consumption ( $k$ cal person ${ }^{-1}$ day $^{-1}$ ), mean minimum dietary energy requirement (MDER), and coefficient of variation (CV) of the domestic distribution of dietary energy consumption in a country. Food distribution in a country is assumed to follow a log-normal distribution determined by the mean dietary energy consumption (mean) and equity of food distribution (variance). The proportion of the population unable to meet the MDER is then defined as the PoU. The calorie-based food consumption (kcal person ${ }^{-1}$ day $^{-1}$ ) output from the models was used as the mean dietary energy consumption. 
The future mean MDER is calculated for each year and country using the mean MDER in the base year at the country level (FAO 2013), coefficients of adjustment for the MDER in different age and gender groups (FAO/WHO 1973), and future population demographics (IIASA 2012) to reflect differences in the MDER across age and gender. The future equity of food distribution is estimated by applying the observed trend of income growth and improved $\mathrm{CV}$ of the food distribution in the base year to the future, so that equity is improved along with income growth at historical rates up to the present best value (0.2) (see Fig. S1 for the future equity of food distribution and (Hasegawa et al. 2015b) for more information about the methodology used to estimate future undernourishment).

The global integrated assessment models (IAMs) and agricultural economic models used in this study are included in Energy Modeling Forum (EMF)33 (Bauer et al. 2018). The goal of EMF33 is to understand and improve the modeling of bioenergy supply and demand in the IAMs (Rose et al. 2014, this issue). We selected six state-of-the-art models that allow us to compute agriculture and land-use market and food-security interactions, considering high bioenergy demand: AIM (Fujimori et al. 2012, 2017; Hasegawa et al. 2017), FARM (Sands et al. 2017), GCAM (Wise et al. 2014), GLOBIOM (Frank et al. 2017; Fricko et al. 2017; Havlík et al. 2014), MAgPIE (Bodirsky et al. 2014; Popp et al. 2014a), and NLU (Brunelle et al. 2015; Souty et al. 2012); Brunelle et al. 2015). AIM, FARM, GCAM, GLOBIOM, and MAgPIE feature land-use competition among food production, bioenergy crop production, and afforestation, whereas NLU employs a food-first policy whereby bioenergy does not compete with food production. AIM, FARM, GCAM, and GLOBIOM endogenously determine food consumption in response to food price or income (in AIM and FARM), whereas MAgPIE and NLU determine food consumption exogenously. We excluded MAgPIE and NLU from results for food consumption and the population at risk of hunger. In each model, the mechanism for land protection is turned off intentionally to remove a factor varying across models and affecting future regional bioenergy potential; no constraint for the protection of land from bioenergy expansion is applied. Notably, the regional classification used in this study is highly aggregated due to the availability of data, which can be improved in future studies.

All of the models have agricultural markets in common, with different representations and parameterizations of biophysical and economic processes. Here, we focus on the endogenous response to the given changes in the underlying socioeconomic conditions and bioenergy impacts. For the demand side, population and income growth increase food demand, shift the demand curve to the right, and raise prices. Responding to the higher price, producers increase their production by expanding cropland and pasture areas and increasing land productivity, while consumers decrease their consumption or shift to less-expensive goods. Some consumers might consume insufficient food and face a risk of hunger. Trade globalization helps to reallocate supply and demand and dampens the impact of producer-side price shocks on consumer prices (Elobeid and Hart 2007; Fackler and Tastan 2008; Nelson et al. 2014; OECD 2006; Shapouri and Rosen 2007; Tyner and Taheripour 2008) and contributes to a lower risk of hunger. Similarly, large-scale bioenergy production increases the demand for land and raises the price of land and then food, resulting in the same responses to the high price (see Fig. S2 for a flow of price transmission from bioenergy implementation to the risk of hunger and Table S1 for a representation of price transmission in the models).

To obtain a comprehensive view of the relationship between bioenergy and food security, we use a set of scenarios from the EMF33 exercise (Rose et al., this issue) that covers two dimensions: (1) different levels of global modern biomass primary energy demand and (2) 
different levels of climate policy, represented by carbon prices. The use of different levels of bioenergy demand allows us to explore the pure effects of bioenergy expansion on food and land-use dynamics. The use of different levels of climate policy allows us to explore the effects of climate-change mitigation efforts on food and land dynamics. Exogenous demand for second-generation bioenergy increases linearly from the base year (2010) to 100, 200, 300, or $400 \mathrm{EJ} \mathrm{year}^{-1}$ by 2100 , with and without the inclusion of climate policy (scenarios B0CB400C and B0-B400, respectively). Most of the models represent climate policy by implementing a global uniform carbon price on greenhouse gas (e.g., $\mathrm{CO}_{2}, \mathrm{CH}_{4}$, and $\mathrm{N}_{2} \mathrm{O}$ ) emissions on agriculture and land-use changes (in all models) and on energy sectors (in AIM, FARM, and GCAM). The carbon price in the scenarios begins at US\$20 per ton $\mathrm{CO}_{2}$-eq in 2020 , with a $3 \%$ annual increase until 2100 , roughly following a carbon path compatible with a $2{ }^{\circ} \mathrm{C}$ climate mitigation target, to enable systematic analysis related to that conducted in a previous study (Kriegler et al. 2015). This exogenous carbon price induces changes in production systems, technological mitigation options, and food demand via consumer responses (the models include changes in preferences due to the price change), and hence decreases emissions. In comparison, scenarios without a carbon price include no responsibility or additional cost for land conversion, forest development, or fertilizer use for biocrop production; these practices normally trigger penalties under the implementation of climate policies. In scenarios with no carbon price, the production cost is low due to the lack of additional costs for land expansion and fertilization compared with that in scenarios with a carbon price. Socioeconomic conditions, including the population, population demographics, and GDP, are varied in each model according to qualitative "middle-of-the-road" (shared socioeconomic pathway (SSP) 2) narratives (Fricko et al. 2017) through 2100. See Rose et al. (this issue) and supplementary table S2 for detailed information on the representation of bioenergy and climate policy in each model.

\section{Results}

\subsection{Bioenergy and food security}

In the baseline scenario, which represents business as usual with no carbon price, the global mean food consumption increases gradually from 2800 to $3000 \mathrm{kcal} \mathrm{cap}^{-1} \mathrm{day}^{-1}$ by 2050 and to $3200 \mathrm{kcal} \mathrm{cap}^{-1}$ day $^{-1}$ (+ $400 \mathrm{kcal}_{\text {person }}^{-1}$ day $^{-1}$ in Asia, $+500 \mathrm{kcal} \mathrm{person}^{-1}$ day $^{-1}$ in the Middle East and Africa (MAF)) by 2100 due to economic growth (Fig. 1). The global undernourished population declines from 830 million people in 2000 to 330 million by 2050 and 150 million (-500 million in Asia, -100 million in MAF) by 2100 . The number of undernourished people has an exponential form reflecting the observed trends in which economic development has largely improved the equity of food distribution, particularly in low-income regions (Supporting information Fig. S1). We also assume a higher rate of economic development in the next few decades relative to that in the last two decades, as the SSPs were developed by focusing on long-term differentiation across SSPs (Dellink et al. 2017). The models agree that food consumption levels remain highest in the Organization for Economic Co-operation and Development (OECD) countries, whereas food consumption starts at the lowest level and catches up with the other regions by the end of this century in the MAF. Model-specific characteristics, however, affect the representation of food consumption. For instance, FARM explores the relatively large population at risk of hunger in the early 
part of the century through the relatively low food consumption assumptions. The food consumption curves in GCAM and NLU bend in 2050 as a consequence of these assumptions. We do not identify differences caused by general model characteristics, such as between partial and general equilibrium models, as the parameter assumptions appear to influence food consumption trends most strongly.

Food prices in the latter half of this century differ markedly across the models (Fig. 1). For example, AIM shows increases exceeding $250 \%$ from the base year (e.g., in Asia), whereas the other models show tendencies of decline from 70 to $90 \%$ of the base-year level for all regions where future agricultural technology development compensates for population growth and increased food demand. Note that AIM, unlike other models, is driven by relative wage increases in developing countries. The undernourished population throughout this century is in good agreement across models in which Asia and the MAF dominate global undernourishment. This model agreement occurs because the future levels of undernourishment depend strongly on the future population, economic development, and equity of food distribution (Hasegawa et al. 2015b), which are harmonized across models, as in the ex-post-method of estimating hunger.

An interesting aspect of bioenergy demand is the pattern of model responses to a bioenergy demand shock. Figure 2 shows the responses of global food-security indicators to different global bioenergy-demand shocks by 2050 under no climate policy (e.g., carbon price is zero) and an intensive bioenergy policy (e.g., driven by biomass subsidies) (see Fig. S3 for the regional responses of food security indicators). Overall, the models agree that high bioenergy demand decreases global food crop production and food and feed available for consumption, and increases undernourishment, although the order of magnitude differs substantially across models (Fig. 2b, h). Higher bioenergy demand increases the price of bioenergy (Fig. 2a), expands cropland area for bioenergy crop production (Fig. 2i), places pressure on the food

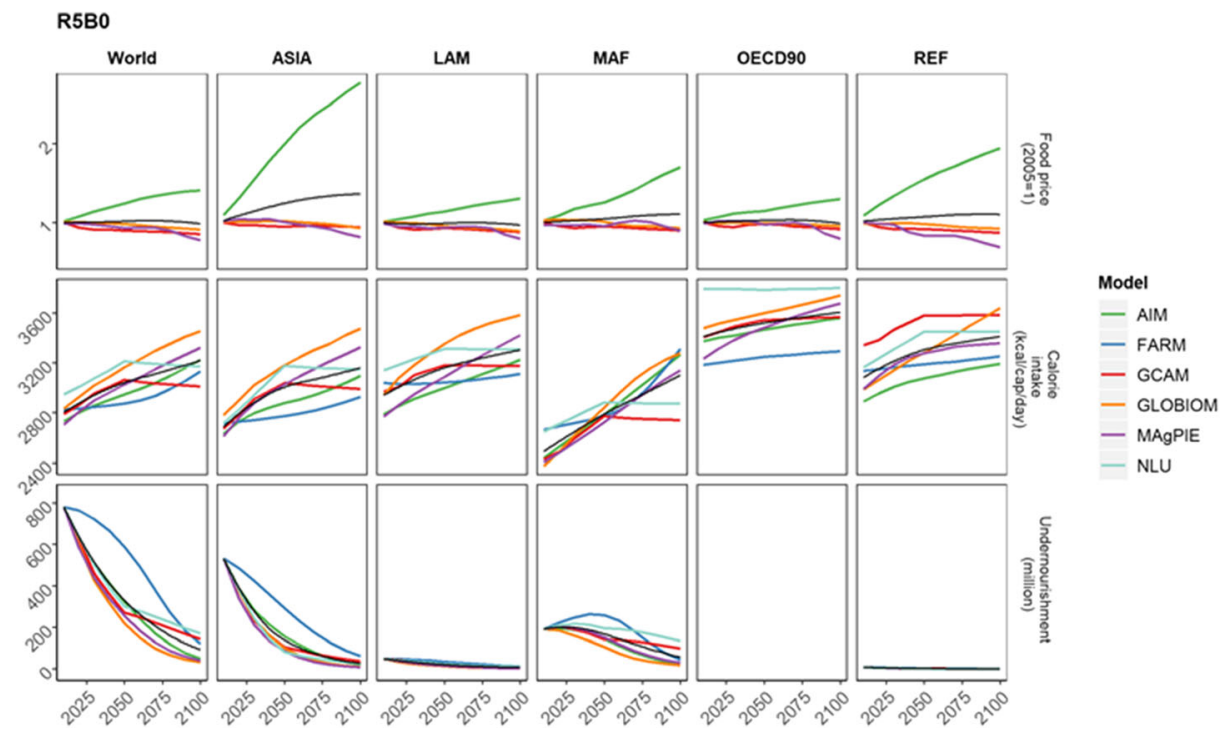

Fig. 1 Food price and consumption and the population at risk of hunger in the baseline scenario with no climate policy (B0) globally and in five regions: Asia, Latin America (LAM), the Middle East and Africa (MAF), Organization for Economic Co-operation and Development regions (OECD90), and reforming economies (REF; Eastern Europe and part of the former Soviet Union). Black lines show the mean values across models 


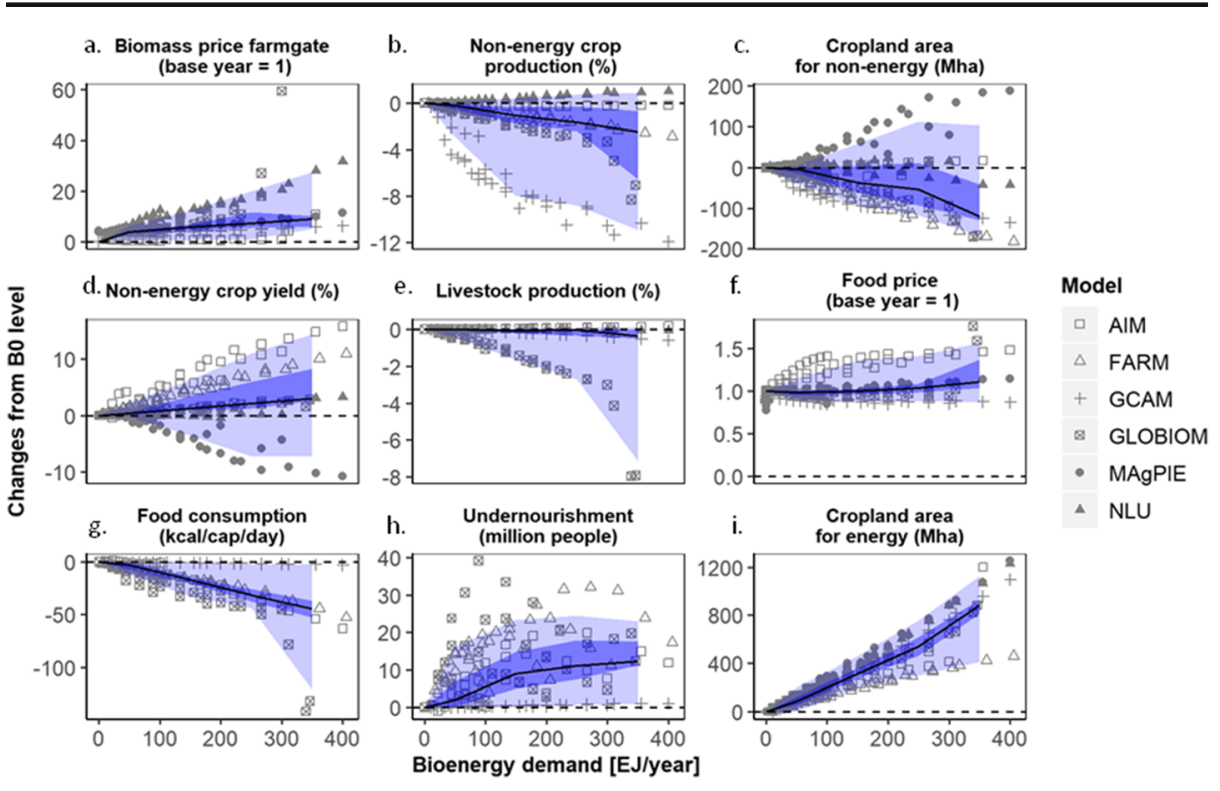

Fig. 2 Global food security indicator responses to various levels of global modern bioenergy demand. Values represent percentage changes from the level of no bioenergy demand (B0). This figure includes all models and years for which the variables are available. Areas show the ranges of the 90th (lighter shading) and 65th (darker shading) percentile values

supply by decreasing the amount of cropland for food production and pasture (Fig. 2c), and then increases food prices (Fig. 2f). In response to the price increase, crop yields generally increase, with the exception that MAgPIE shows movement from currently productive areas to unproductive areas of cropland (Fig. 2d; see Fig. 3 for land conversion under different levels of bioenergy implementation across models). As cropland intensification is insufficient to meet the food demand, food production decreases (Fig. 2b). Consequently, food consumption decreases (Fig. 2g), leading to more undernourishment (Fig. 2h). For instance, the global
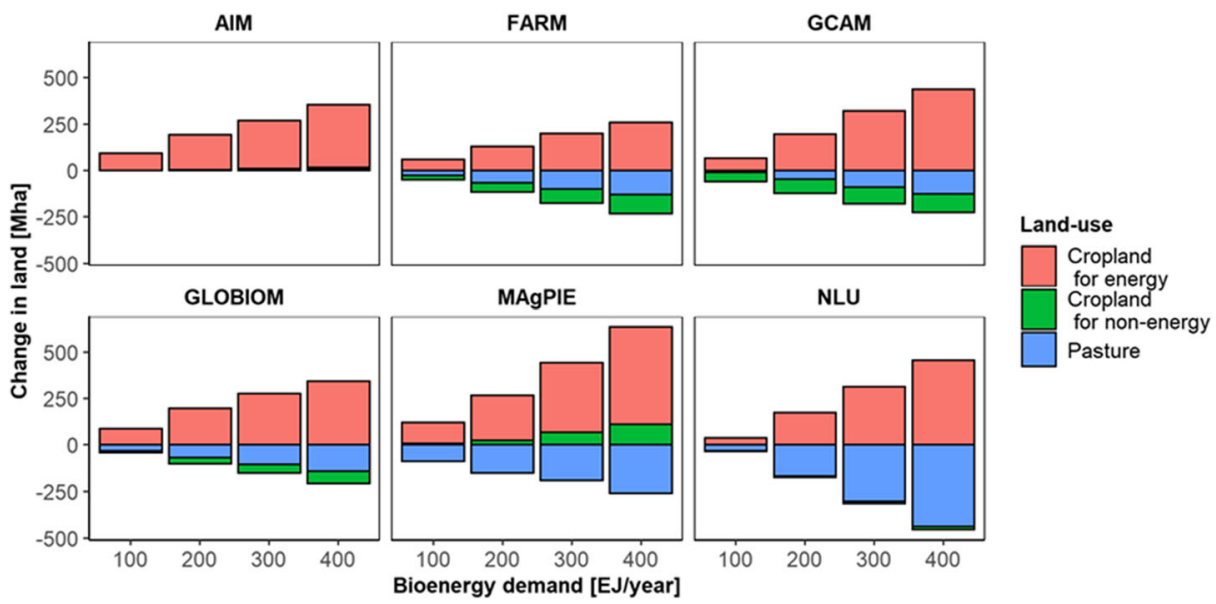

Fig. 3 Land-use changes under different levels of bioenergy implementation in 2050 in different models. The regional codes are the same as in Fig. 1 
bioenergy demand of 200-300 EJ year ${ }^{-1}$ is expected to expand the area of cropland for biocrops by 540 Mha and shrink the area of cropland for food production and pasture by $53 \mathrm{Mha}$, increasing the global crop production by $2.8 \%$, food prices by $3.5 \%$, and the number of undernourished people by 11 million, in the median across scenarios with no bioenergy demand. The direction of change is the same in most models, with some exceptions (Figs. 2 and 3). In MAgPIE, bioenergy implementation leads to the replacement of cropland areas suitable for high-yield crop production with those used for biomass crops (thus, cropland becomes unavailable for food crops); crop yields then become low, spurring cropland expansion to meet food demand. AIM locates bioenergy production in currently unused areas, and thus shows less impact on food production and the area it occupies (the assumptions and modeling strategy are described in Fujimori et al. 2014).

The food price response to bioenergy implementation can be compared with the findings of Lotze-Campen et al. (2014), who reported change ratios of 2-8\% in 2050 compared with the baseline scenario and a bioenergy implementation level of 100 EJ. Our results appear to be in line with those results (Fig. 2). Notably, we used multi-scale bioenergy implementation levels, which enabled us to investigate the responses of food price and consumption systematically, which is a novel aspect of this study.

The degree of the response to a bioenergy demand shock varies significantly across models and indicators. For example, an increase in global bioenergy demand from 200 to $300 \mathrm{EJ}$ causes -11 to $+40 \%$ changes in food crop price and a decrease in food consumption from 45 to $-2 \mathrm{kcal}^{\text {person }}{ }^{-1}$ day $^{-1}$, leading to an additional 0 to 25 million people at risk of hunger in the no bioenergy demand case (90th percentile range across models). The results derived from models depend on their assumptions, such as those regarding land capacity and potential land productivity, as well as model structure. For example, in models that assume high-yield development in response to high prices (e.g., AIM, FARM), the reduction in food production can be overcome by increasing yield, and changes in price and food consumption can be minimized. On the other hand, if yield improvement is assumed to be relatively low (e.g., GLOBIOM, NLU), the bioenergy shock on food supply or price is relatively large. The proportions of meat and crops in the total caloric intake do not vary with differences in bioenergy demand (Fig. 4). As the increased demand due to bioenergy does not affect consumption patterns, these patterns do not mitigate the pressures that bioenergy production places on land use and food availability.

\subsection{Responses to bioenergy demand shock in terms of food security}

Figure 5 shows the global and regional responses of food security indicators to a 200-EJ global bioenergy demand shock under no climate policy in 2050. Generally, the response on the production side (e.g., crop yields and cropland area) is more heterogeneous than that on the consumption side (e.g., food consumption and undernourishment). The bioenergy demand shock is absorbed primarily by the agricultural production side, reflected largely in yield changes and partly in area changes (Fig. 2). This situation may occur for several reasons. First, a bioenergy demand shock is directed at the production side, through competition for land and other resources, which markedly limits food production capacity. Second, per-capita food consumption has a biological limit and is relatively inelastic to changes in price relative to supply-side factors. In other words, the price elasticity of food demand is relatively low (Nelson et al. 2014) (see Fig. S4 for the consumption response to price changes). Changes in the risk of hunger are large in Asia and the MAF, and reforming economies (Eastern Europe 


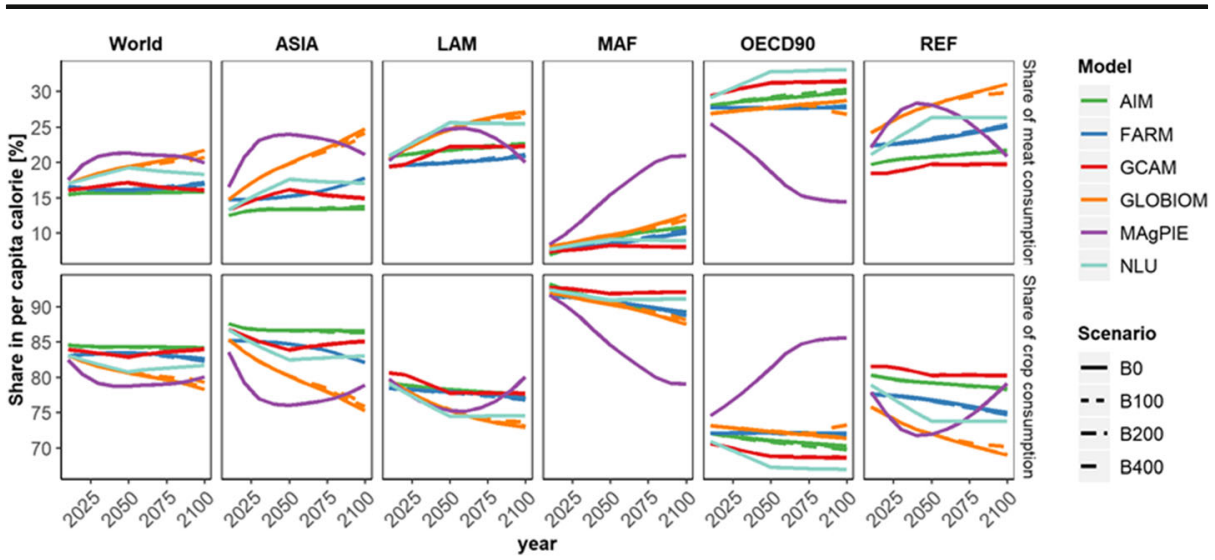

Fig. 4 Proportions of meat and crops in the per-capita food (calorie) consumption worldwide and in various regions under scenarios with different levels of bioenergy demand in this century. B0 is the scenario with no climate policy and no bioenergy demand. B100, B200, and B400 are the scenarios in which global bioenergy demand achieves 100, 200, and $400 \mathrm{EJ}$ year $^{-1}$, respectively, by 2100

and part of former Soviet Union) also show a relatively strong response but with small absolute numbers. Non-energy cropland area decreased in all models (excluding MAgPIE, which is not relevant to the food consumption assessment). Thus, most of the bioenergy effects arise directly from regional bioenergy expansion.

In the supply response, the levels and direction of changes in crop yields and cropland area are heterogeneous across models. These differences are generated by model representations of potential yield and its improvement costs (e.g., substitution of other inputs for land), land transition costs (e.g., elasticity of substitution across land types), and land capacity (e.g., area of land suitable for crops). Therefore, the tradeoff between land intensification and land expansion varies across models.

Global indicators of food security are important, but regional estimates are more useful to policymakers. Many models agree that bioenergy demand shocks increase food prices, leading to changes in yield, decreasing food consumption, and affecting undernourishment in many
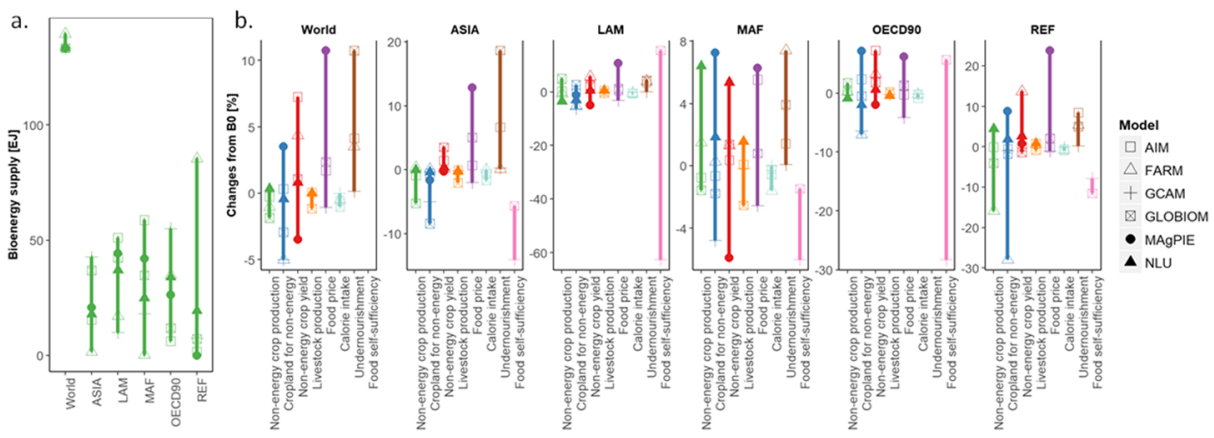

Fig. 5 Global and regional responses of food security indicators to a 133-EJ global modern bioenergy demand, which is represented by the year 2050 in scenario B300, in which the global bioenergy demand achieves 300 EJ by 2100 . a Regional share of bioenergy supply. b The values are percentage changes from no bioenergy demand (B0). MAgPIE and NLU were excluded from per-capita food calorie consumption, undernourishment, and food self-sufficiency assessment due to demand-side inelasticity, and NLU was excluded from the price assessment. Few models are available for the examination of food self-sufficiency because weight-based livestock data are not available 
areas of the world (Figs. 5b and 6). However, regional heterogeneity across models is much larger than is apparent when comparing global averages. The regional allocation of bioenergy production is quite heterogeneous across models due to the varying representation of bioenergy production (Fig. 5a; see Rose et al., this issue). In large bioenergy-producing regions, a large increase in food price, large decrease in food consumption, and increase in hunger do not necessarily occur. These responses vary depending on the regional land availability and potential intensification, price, and income elasticity of food demand, and regional differences in the baseline levels of food consumption and distribution, which determine the population experiencing long-term hunger. For example, food production in Latin America increases through improved crop yields and cropland expansion, responding to a price increase and reallocation of the food supply to more efficient countries through international trade. By contrast, for Asia, which is also expected to be a large potential bioenergy production region, most models (except MAgPIE) show decreases in the area of cropland used for food production due to the limited area of suitable cropland, leading to a large decrease in food production and lower food self-sufficiency. In Africa, the crop production results vary across models due to the varying potential crop yield and available cropland area under climate mitigation. Climate mitigation leads to increased crop yields, but decreased area of land for food production, in most models, with the exception of NLU and MAgPIE.

\subsection{Effect of climate change mitigation on food security}

To isolate the effect of climate policy under different levels of bioenergy supply, we examine the differences between scenarios with and without carbon prices under three levels of bioenergy demand (Fig. 7). The models show two important results. First, the models all show a stronger climate policy (higher carbon price) more negatively affects food consumption and undernourishment, regardless of the amount of bioenergy. Second, the magnitude of the climate mitigation effects varies across models due to the representation of climate mitigation and mitigation technological possibilities. GLOBIOM is most affected by the mitigation policy ( $-6 \%$ food consumption for $200 \$ / \mathrm{tCO}_{2}$ ), and AIM and FARM are affected the least. Previous research yielded a similar result (Hasegawa et al. 2015a, 2018), showing that the impact of climate policy on food security is explained by bioenergy through land competition, and in

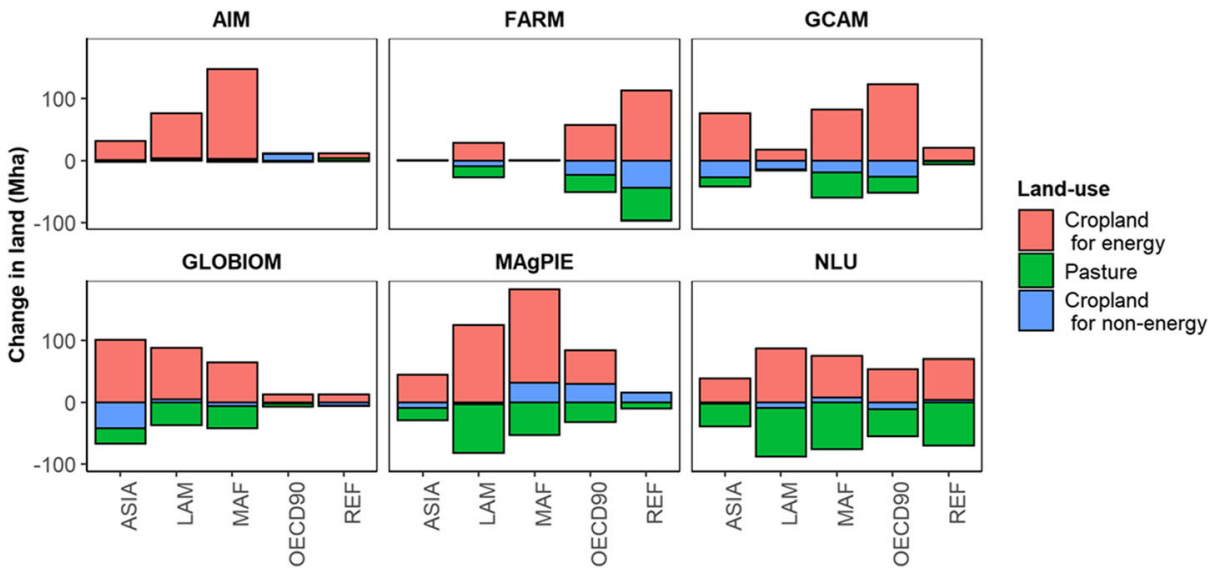

Fig. 6 Regional land-use changes caused by a 133-EJ global modern bioenergy demand (B300 in 2050) 

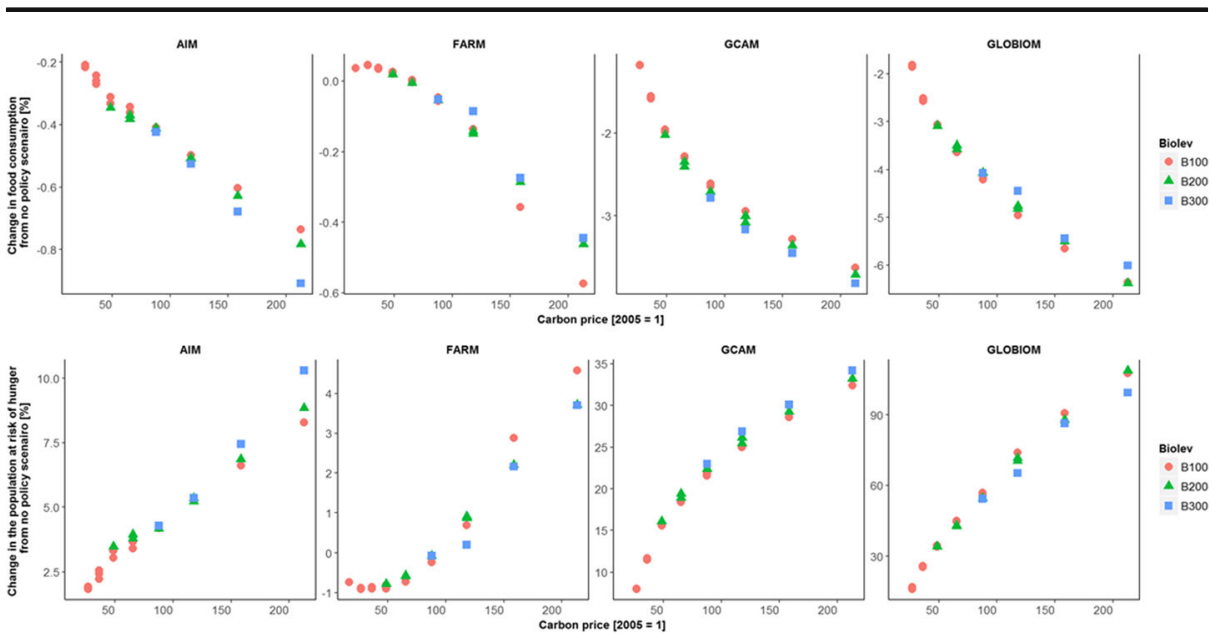

Fig. 7 Mitigation impacts on food consumption and the undernourished population under different carbon prices for the bioenergy demand (100, 200, and $300 \mathrm{EJ}$; B100C-B100, B200C-B200, and B300C-B300, respectively). NLU and MAgPIE are excluded because they assume inelastic food demand. The scales differ across panels. This figure includes the years in which the bioenergy demand is equivalent to the above values

part by mitigation tied directly to a carbon price. The relative sizes of these two effects vary across models depending on the range of mitigation options available.

\section{Discussion and conclusion}

Climate change and mitigation measures have three major effects on food consumption and the risk of hunger: (1) changes in crop yield caused by climate change; (2) competition for land between food and energy crop production driven by the use of bioenergy; and (3) the implementation of other agriculture-related mitigation measures to meet an emissions reduction target that limits the global average temperature increase to 1.5 or $2{ }^{\circ} \mathrm{C}$ (Hasegawa et al. 2015a). Ideal climate policy would achieve a balance among these effects. This study does not address the impact of climate on crop yields, but reduced climate impacts on agriculture provide motivation for reductions in carbon dioxide emissions.

Through careful scenario design, this study isolates the effect of competition for land between food and energy crop production. Our analysis suggests that large-scale bioenergy use would put pressure on agricultural land, raising food prices and increasing the population at risk of hunger across world regions. We use a probability distribution framework to estimate the population at risk of hunger in each world region. Options to reduce the impact on foodinsecure populations include additional research to improve agricultural productivity and economic compensation for those at greatest risk.

Several factors affect the level of food insecurity under high bioenergy demand. First, potential yields of food and bioenergy crops determine the land demand for future food and bioenergy production, and the level of land-use conflict and food insecurity. High land productivity, such as that achieved with technological development to improve the efficiency of irrigation and fertilizer implementation, and improved human capital would reduce the food insecurity caused by bioenergy implementation. As we do not harmonize crop yields across the models in our analysis, further diagnostic studies that decompose supply-side technologies 
would improve our understanding of how agricultural technology development would reduce food insecurity. Second, the type of feedstock could change the level of food insecurity. Reliance on bioenergy only from energy crops increases land competition and the impact on food production and then consumption, whereas bioenergy supplied from crop residue and managed forest reduces the land available for bioenergy production and affects food security. The influence on food security can be relaxed by combining energy derived from residue and managed forest, although the potential of forest and residues is limited.

Although we saw some model agreement, the results differed among models. We attempted to classify the variation among model types, such as that between partial and general equilibrium models, but observed no systematic difference. Instead, we observed that food price elasticity is a key parameter affecting food consumption and that the risk of hunger responds to shocks, including bioenergy implementation. Income elasticity for food consumption is another major driver of baseline food consumption that should be explored (Fig. 1), but it is not the main contributor to the risk of hunger associated with bioenergy demand shocks.

Despite recent advances in global crop model development, the large regional heterogeneity in the response to bioenergy demand, particularly on the production side (e.g., crop yields and cropland area), suggests that the situation for the agricultural supply side remains uncertain. First, information on agricultural production technologies remains limited; for example, the costs of technology development and agricultural production, management, and land conversion, possible technologies, and their regional availability vary across models with different assumptions. The development of a global agricultural production database would help to narrow the range of model uncertainty. Second, the distribution of energy crop productivity remains uncertain. More knowledge of the projected bioenergy potential would enable us to assess the bioenergy potential and its consequences on food security at the regional level more accurately (see Rose et al., this issue, for more discussion of bioenergy supply comparison).

Several points should be considered when interpreting our results. First, a uniform carbon price across regions was used in the multi-model ensemble to simulate mitigation in agriculture, which implies a burden of mitigation on medium- and low-income regions. The contributions of these regions to such mitigation schemes should be treated carefully because these regions are most vulnerable to climate change. We used this common approach across models, but further research is needed to address how the different contributions of these regions would affect the regional food situations. Second, the same carbon price is set across sectors (agriculture and energy), as required for economic efficiency. The taxing of emissions in the agricultural sector is not always good for food security, as this study shows. However, exclusion of the agricultural contribution of non- $\mathrm{CO}_{2}$ emission reduction would require much larger such reduction in other sectors, and may be very costly or even insufficient to reach climate change goals (Gernaat et al. 2015; Reisinger et al. 2013; Wollenberg et al. 2016). Further study of non- $\mathrm{CO}_{2}$ emission reduction policies is required to address this issue. Third, most of the models respond to the given bioenergy demand based on economic efficiency, but do not necessarily minimize food security. Regional allocation of bioenergy production and the allocation of land between food and bioenergy production are selected to maximize farmers' profit or minimize production costs. Fourth, this study does not consider heterogeneity among domestic income groups in responses to changes in food consumption due to increased consumer food prices, although such heterogeneity may exist in the real world. Finally, most of the models used in this study consider competition for land 
between food and bioenergy production, but do not explicitly harmonize other aspects of the environment, such as biodiversity protection, which would constrain the future bioenergy potential. When exploring the path toward sustainable development, consideration of these interactions is important.

Acknowledgments T.H. and S.F. acknowledge support from Yuki Ochi for creating the hunger estimation tool for the multiple models. The findings and conclusions in this publication are those of the authors and should not be construed to represent any official USDA or U.S. Government determination or policy.

Author contributions T.H. coordinated the conception, led the writing of the paper, and created the figures. T.H. and S.F. designed the research, created the hunger estimation tool for the multiple models, and performed the scenario analysis of the modeling results with notable contributions from T.H., S.F. (AIM/CGE), R.D.S. (FARM), Y.C. (GCAM), S.F.(GLOBIOM), A.P. (MAgPIE), and T.B. (NLU); all authors provided feedback and contributed to writing the paper.

Funding information T.H. and S.F. acknowledge support from the Environment Research and Technology Development Fund (JPMEERF20202002) of the Environmental Restoration and Conservation Agency of Japan, the Japan Society for the Promotion of Science KAKENHI (grant no. 19 K24387), and the Sumitomo Foundation. T.B. received support from the ANR CLAND Institute of Convergence (16-CONV-0003). This research was supported in part by the U.S. Department of Agriculture, Economic Research Service.

\section{Compliance with ethical standards}

Competing interests The authors declare that they have no competing interest.

Open Access This article is licensed under a Creative Commons Attribution 4.0 International License, which permits use, sharing, adaptation, distribution and reproduction in any medium or format, as long as you give appropriate credit to the original author(s) and the source, provide a link to the Creative Commons licence, and indicate if changes were made. The images or other third party material in this article are included in the article's Creative Commons licence, unless indicated otherwise in a credit line to the material. If material is not included in the article's Creative Commons licence and your intended use is not permitted by statutory regulation or exceeds the permitted use, you will need to obtain permission directly from the copyright holder. To view a copy of this licence, visit http://creativecommons.org/licenses/by/4.0/.

\section{References}

Bauer N, Rose SK, Fujimori S, van Vuuren DP, Weyant J, Wise M, Cui Y, Daioglou V, Gidden MJ, Kato E, Kitous A, Leblanc F, Sands R, Sano F, Strefler J, Tsutsui J, Bibas R, Fricko O, Hasegawa T, Klein D, Kurosawa A, Mima S, Muratori M (2018) Global energy sector emission reductions and bioenergy use: overview of the bioenergy demand phase of the EMF-33 model comparison. Clim Chang

Bodirsky BL, Popp A, Lotze-Campen H, Dietrich JP, Rolinski S, Weindl I, Schmitz C, Müller C, Bonsch M, Humpenöder F, Biewald A, Stevanovic M (2014) Reactive nitrogen requirements to feed the world in 2050 and potential to mitigate nitrogen pollution. Nat Commun 5:3858

Brunelle T, Dumas P, Souty F, Dorin B, Nadaud F (2015) Evaluating the impact of rising fertilizer prices on crop yields. Agric Econ 46:653-666

Cafiero C (2014) Advances in hunger measurement: traditional FAO methods and recent innovations. In: Series FSDWP (ed) Food and Agriculture Organization of the United Nation, Rome

Dellink R, Chateau J, Lanzi E, Magné B (2017) Long-term economic growth projections in the shared socioeconomic pathways. Glob Environ Chang 42:200-214

Elobeid A, Hart C (2007) Ethanol expansion in the food versus fuel debate: how will developing countries fare? Journal of Agricultural \& Food Industrial Organization

Fackler PL, Tastan H (2008) Estimating the degree of market integration. Am J Agric Econ 90:69-85 
FAO (2013) Food security indicators. In: FAO (ed) Rome, Italy

FAO (2016) Food security indicators. In: FAO (ed) Rome, Italy

FAO/WHO (1973) Energy and protein requirements. WHO technical report series No. 522 FAO nutrition meetings report series No. 52. FAO/WHO, Geneva, Switzerland

Frank S, Havlík P, Soussana J-F, Levesque A, Valin H, Wollenberg E, Kleinwechter U, Fricko O, Gusti M, Herrero M, Smith P, Hasegawa T, Kraxner F, Obersteiner M (2017) Reducing greenhouse gas emissions in agriculture without compromising food security? Environ Res Lett 12:105004

Fricko O, Havlik P, Rogelj J, Klimont Z, Gusti M, Johnson N, Kolp P, Strubegger M, Valin H, Amann M, Ermolieva T, Forsell N, Herrero M, Heyes C, Kindermann G, Krey V, McCollum DL, Obersteiner M, Pachauri S, Rao S, Schmid E, Schoepp W, Riahi K (2017) The marker quantification of the shared socioeconomic pathway 2: a middle-of-the-road scenario for the 21st century. Glob Environ Chang 42: 251-267

Fujimori S, Masui T, Matsuoka Y (2012) AIM/CGE [basic] manual. Discussion paper series. Center for Social and Environmental Systems Research, NIES, Tsukuba, Japan

Fujimori S, Hasegawa T, Masui T, Takahashi K (2014) Land use representation in a global CGE model for longterm simulation: CET vs. logit functions. Food Sec 6:685-699

Fujimori S, Hasegawa T, Masui T, Takahashi K, Herran DS, Dai H, Hijioka Y, Kainuma M (2017) SSP3: AIM implementation of shared socioeconomic pathways. Glob Environ Chang 42:268-283

Fujimori S, Hasegawa T, Krey V, Riahi K, Bertram C, Bodirsky BL, Bosetti V, Callen J, Després J, Doelman J, Drouet L, Emmerling J, Frank S, Fricko O, Havlik P, Humpenöder F, Koopman JFL, van Meijl H, Ochi Y, Popp A, Schmitz A, Takahashi K, van Vuuren D (2019) A multi-model assessment of food security implications of climate change mitigation. Nat Sustain 2:386-396

Gernaat DEHJ, Calvin K, Lucas PL, Luderer G, Otto SAC, Rao S, Strefler J, van Vuuren DP (2015) Understanding the contribution of non-carbon dioxide gases in deep mitigation scenarios. Glob Environ Chang 33:142-153

Hasegawa T, Fujimori S, Shin Y, Tanaka A, Takahashi K, Masui T (2015a) Consequence of climate mitigation on the risk of hunger. Environ Sci Technol 49:7245-7253

Hasegawa T, Fujimori S, Takahashi K, Masui T (2015b) Scenarios for the risk of hunger in the twenty-first century using shared socioeconomic pathways. Environ Res Lett 10:014010

Hasegawa T, Fujimori S, Ito A, Takahashi K, Masui T (2017) Global land-use allocation model linked to an integrated assessment model. Sci Total Environ 580:787-796

Hasegawa T, Fujimori S, Havlík P, Valin H, Bodirsky BL, Doelman JC, Fellmann T, Kyle P, Koopman JFL, Lotze-Campen H, Mason-D’Croz D, Ochi Y, Pérez Domínguez I, Stehfest E, Sulser TB, Tabeau A, Takahashi K, Jy T, van Meijl H, van Zeist W-J, Wiebe K, Witzke P (2018) Risk of increased food insecurity under stringent global climate change mitigation policy. Nat Clim Chang 8:699-703

Havlík P, Valin H, Herrero M, Obersteiner M, Schmid E, Rufino MC, Mosnier A, Thornton PK, Böttcher H, Conant RT, Frank S, Fritz S, Fuss S, Kraxner F, Notenbaert A (2014) Climate change mitigation through livestock system transitions. Proc Natl Acad Sci 111:3709-3714

Havlík P, Valin H, Gusti M, Schmid E, Leclère D, Forsell N, Herrero M, Khabarov N, Mosnier A, Cantele M, Obersteiner M (2015) Climate change impacts and mitigation in the developing world: an integrated assessment of the agriculture and forestry sectors. Policy Research Working Paper No. WPS 7477

IIASA (2012) Shared socioeconomic pathways (SSP) database version 0.9.3

Kriegler E, Petermann N, Krey V, Schwanitz VJ, Luderer G, Ashina S, Bosetti V, Eom J, Kitous A, Méjean A, Paroussos L, Sano F, Turton H, Wilson C, Van Vuuren DP (2015) Diagnostic indicators for integrated assessment models of climate policy. Technol Forecast Soc Chang 90:45-61

Lotze-Campen H, von Lampe M, Kyle P, Fujimori S, Havlik P, van Meijl H, Hasegawa T, Popp A, Schmitz C, Tabeau A, Valin H, Willenbockel D, Wise M (2014) Impacts of increased bioenergy demand on global food markets: an AgMIP economic model intercomparison. Agric Econ 45:103-116

Nelson GC, Valin H, Sands RD, Havlík P, Ahammad H, Deryng D, Elliott J, Fujimori S, Hasegawa T, Heyhoe E, Kyle P, Von Lampe M, Lotze-Campen H, Mason d'Croz D, van Meijl H, van der Mensbrugghe D, Müller C, Popp A, Robertson R, Robinson S, Schmid E, Schmitz C, Tabeau A, Willenbockel D (2014) Climate change effects on agriculture: economic responses to biophysical shocks. Proc Natl Acad Sci 111: 3274-3279

OECD (2006) Agricultural market impacts of future growth in the production of biofuels. OECD Pap 6:1-1

Popp A, Humpenöder F, Weindl I, Bodirsky BL, Bonsch M, Lotze-Campen H, Müller C, Biewald A, Rolinski S, Stevanovic M, Dietrich JP (2014a) Land-use protection for climate change mitigation. Nat Clim Chang 4: 1095

Popp A, Rose SK, Calvin K, Van Vuuren DP, Dietrich JP, Wise M, Stehfest E, Humpenöder F, Kyle P, Van Vliet J, Bauer N, Lotze-Campen H, Klein D, Kriegler E (2014b) Land-use transition for bioenergy and 
climate stabilization: model comparison of drivers, impacts and interactions with other land use based mitigation options. Clim Chang 123:495-509

Popp A, Calvin K, Fujimori S, Havlik P, Humpenöder F, Stehfest E, Bodirsky BL, Dietrich JP, Doelmann JC, Gusti M, Hasegawa T, Kyle P, Obersteiner M, Tabeau A, Takahashi K, Valin H, Waldhoff S, Weindl I, Wise M, Kriegler E, Lotze-Campen H, Fricko O, Riahi K, Vuuren DPV (2017) Land-use futures in the shared socio-economic pathways. Glob Environ Chang 42:331-345

Reisinger A, Havlik P, Riahi K, van Vliet O, Obersteiner M, Herrero M (2013) Implications of alternative metrics for global mitigation costs and greenhouse gas emissions from agriculture. Clim Chang 117:677-690

Rose S, Kriegler E, Bibas R, Calvin K, Popp A, van Vuuren D, Weyant J (2014) Bioenergy in energy transformation and climate management. Clim Chang 123:477-493

Sands RD, Malcolm SA, Suttles SA, Marshall E (2017) Dedicated energy crops and competition for agricultural land. Economic research report no. 223. United States. Department of Agriculture. Economic Research Service, Washington. D.C., United States

Shapouri S, Rosen S (2007) Energy price implications for food security in developing countries. Food Security Assessment. USDA

Souty F, Brunelle T, Dumas P, Dorin B, Ciais P, Crassous R, Müller C, Bondeau A (2012) The Nexus land-use model version 1.0, an approach articulating biophysical potentials and economic dynamics to model competition for land-use. Geosci. Model Dev 5:1297-1322

Tyner W, Taheripour F (2008) Policy options for integrated energy and agricultural markets*. Rev Agric Econ $30: 387-396$

UNFCCC (2015) United Nations framework convention on climate change, adoption of the Paris Agreement. Proposal by the President (1/CP21). Available from: http://unfccc.int/resource/docs/2015/cop21/eng/10a01. pdf. Accessed 2 Feb 2016

Wise M, Calvin K, Kyle P, Luckow P, Edmonds J (2014) Economic and physical modeling of land use in GCAM 3.0 and an application to agricultural productivity, land, and terrestrial carbon. Clim Chang Econ 05: 1450003

Wollenberg E, Richards M, Smith P, Havlík P, Obersteiner M, Tubiello FN, Herold M, Gerber P, Carter S, Reisinger A, van Vuuren DP, Dickie A, Neufeldt H, Sander BO, Wassmann R, Sommer R, Amonette JE, Falcucci A, Herrero M, Opio C, Roman-Cuesta RM, Stehfest E, Westhoek H, Ortiz-Monasterio I, Sapkota T, Rufino MC, Thornton PK, Verchot L, West PC, Soussana J-F, Baedeker T, Sadler M, Vermeulen S, Campbell BM (2016) Reducing emissions from agriculture to meet the $2{ }^{\circ} \mathrm{C}$ target. Glob Chang Biol 22: 3859-3864

Publisher's note Springer Nature remains neutral with regard to jurisdictional claims in published maps and institutional affiliations.

\section{Affiliations}

\section{Tomoko Hasegawa $^{1,2,3} \cdot$ Ronald D. Sands ${ }^{4} \cdot$ Thierry Brunelle $^{5} \cdot$ Yiyun Cui $^{6} \cdot$ Stefan Frank $^{3} \cdot$ Shinichiro Fujimori ${ }^{2,3,7} \cdot$ Alexander Popp $^{8}$}

1 Ritsumeikan University, 1-1-1, Nojihigashi, Kusatsu, Shiga 525-8577, Japan

2 Center for Social and Environmental Systems Research, National Institute for Environmental Studies (NIES), 16-2 Onogawa, Tsukuba, Ibaraki 305-8506, Japan

3 International Institute for Applied Systems Analysis (IIASA), Schlossplatz 1, 2361 Laxenburg, Austria

4 U.S. Department of Agriculture, Economic Research Service Beacon Facility MS 9999, P.O. Box 419205, Kansas City, MO 64141, USA

5 CIRAD, UMR CIRED, 94736 Nogent-sur-Marne, France

6 Pacific Northwest National Laboratory (PNNL), 5825 University Research Court, Suite 3500, College Park, MD 20740, USA

7 Department of Environmental Engineering, Graduate School of Engineering, Kyoto University, C1-3, Kyoto Daigaku Katsura, Nishikyo-ku, Kyoto-shi 615-8540, Japan

8 Potsdam Institute for Climate Impact Research (PIK), Telegrafenberg A 31, 14473 Potsdam, Germany 